\title{
PUBLICIDADE E PÚBLICO INFANTIL: A INFLUÊNCIA DE MÍDIAS SOCIAIS E A PROTEÇÃO DA INFÂNCIA
}

\author{
Ana Emília Bressan Garcia ${ }^{1}$ \\ Valdir Garcia dos Santos Júnior ${ }^{2}$
}

\begin{abstract}
RESUMO: A publicidade é o mecanismo impulsionador do capitalismo, visto que para a movimentação de aquisição e venda é uma ferramenta primordial. Mas se torna um problema que requer atenção e proteção quando fortemente inserida no contexto infantil, visto que, incorporada na formação de personalidade humana acarretará problemas, tanto durante a infância, quanto na vida adulta em seu convívio social. Nesse sentido, é indispensável que se analise questões como a adequação da publicidade, de acordo com a idade e capacidade de compreensão da criança, consequências desta, entre outros assuntos, cabendo ao direito, pais e sociedade como um todo zelar pelo bem-estar das crianças e adolescentes, em especial no atual contexto social, que oferece maior facilidade para se ter acesso à publicidade. No presente estudo se analisou a respeito da influência das mídias sociais no contexto infantil e juvenil, bem como medidas para se evitar problemas, sejam estes presentes ou futuros. Para tanto se fez o uso do método dedutivo-indutivo, com revisão bibliográfica.
\end{abstract}

PALAVRAS-CHAVE: Direitos da Criança e do Adolescente; Medidas de Proteção; Tecnologias Atuais.

\section{PUBLICITY AND CHILDREN: THE INFLUENCE OF SOCIAL MEDIA AND THE PROTECTION OF CHILDHOOD}

\begin{abstract}
Advertising is the driving force of capitalism, since for the movement of acquisition and sale is a primordial tool. But it becomes a problem that requires attention and protection when strongly inserted in the children's context, since, incorporated in the formation of human personality will cause problems, both during childhood and adult life in their social life. In this sense, it is essential to analyze issues such as the adequacy of advertising, according to the child's age and comprehension capacity, consequences of this, among other issues, it being up to the law, parents and society as a whole to ensure the welfare of children. children and adolescents, especially in the current social context, which makes it easier to access advertising. The present study analyzed the influence of social media in the context of children and youth, as well as measures to avoid problems, whether present or future. For that, the deductive-inductive method was used, with a bibliographic review.
\end{abstract}

KEYWORDS: Rights of Children and Adolescents; Protective Measures; Current Technologies.

\footnotetext{
${ }^{1}$ Mestranda em Direito pela Universidade de Marília. Advogada e professora universitária, graduada em 2002 pelo Centro Universitário Toledo de Araçatuba/SP, onde atualmente ministra aulas nos cursos de Publicidade e Propaganda e Gestão de Recursos Humanos. Pós graduada em Direito Processual, Docência no Ensino Superior e Direito e Processo do Trabalho pela mesma instituição onde se graduou e onde ministra aulas. Sócia no escritório Nilson Faria Advogados Associados.

${ }^{2}$ Advogado, bacharel em direito pelo Unitoledo de Araçatuba e mestre em direito pelo Univem de Marília
} 


\section{INTRODUÇÃO}

Crianças e adolescentes estão cada dia mais envoltos na tecnologia, contudo, é preciso bastante cuidado, a fim de que tal fato não gere problemas na formação do indivíduo.

Sistemas capitalistas tornam o consumo uma necessidade iminente e, para aqueles que não sabem dosar a oferta e a publicidade apelativa com suas necessidades, podem se ver dependentes do consumo, o que pode ocasionar problemas de ordem financeira, psicológica, entre outras.

Insta salientar, analisando a evolução humana em seu decorrer, que o homem sempre foi possuidor de caráter consumista, e em contrapartida, com a expansão do capitalismo o ser humano precisou vender e ofertar, qualificando os métodos e ferramentas para tal atividade, sendo o mais importante destes mecanismos a publicidade.

Assim, acerca da publicidade Gonçales $(2009$, p.7) diz que "é conceituada como a arte de tornar público, divulgar um fato ou uma ideia, já com objetivos comerciais, uma vez que pode despertar o desejo de compra, levando-o à ação". É um conjunto de técnicas de ação coletiva com o propósito de tornar conhecido um produto, um serviço, uma marca, promovendo assim uma atividade comercial.

Nesse sentido, quando a publicidade é direcionada para o público infanto-juvenil, é preciso cuidado, uma vez que as crianças e adolescentes nem sempre estão preparadas para entender que se trata de publicidade e não de uma necessidade iminente de vida.

Gonçales (2009, p. 7) também afirma que "a publicidade e a propaganda se caracterizam principalmente pela persuasão, ou o ato de convencer com argumentos (verdadeiros ou não), as pessoas sobre qualquer assunto".

Assim, no presente estudo se analisou acerca da influência para a sociedade da publicidade, que é tida como relevante ferramenta do consumo, tendo como principal foco o público infantil, visto que a criança não nasce um ser humano consumista e sim adquire em seu ambiente de crescimento, através de fatores exógenos, acarretando problemáticas sociais para sua personalidade adulta. 


\title{
1 AS MÍDIAS E A INFLUÊNCIA NA VIDA SOCIAL
}

Cada dia mais o mundo se torna tecnológico e digital, e as pessoas estão cada vez mais conectadas e dependentes da mídia.

Nesse sentido, é inevitável ser influenciado pelas mídias sociais, uma vez que fazem parte do cotidiano, independentemente de se tratar de uma criança, adolescente, adulto ou idoso.

Segundo Meireles (2006, p. 21):

\begin{abstract}
Na última década os meios de comunicação foram diretamente afetados pelo processo de globalização, avanços tecnológicos e desregulamentação do setor de telecomunicações. A informação se universalizou e passou a invadir os lares com rapidez atingindo em poucos segundos bilhões de pessoas. Os meios de comunicação como revistas, jornais, rádio e televisão, instrumentos potenciais que designam a mídia, se popularizaram de tal forma que é praticamente impossível permanecer alheio às suas influências...
\end{abstract}

A globalização, portanto, trouxe muitas mudanças, dentre as quais inseriu grandes tecnologias no cotidiano, como a internet, o que diminuiu as distâncias, transformou completamente a forma como de se comunicar e interagir.

Nesse sentido, as mídias fazem parte da vida, influenciando a sociedade a todo instante, influenciando o imaginário das pessoas, assim,

O convívio com a mídia é uma realidade diária em nossa vida. Ao acordar pela manhã a televisão apresenta as últimas notícias e o rádio, por sua vez, faz o mesmo. Da mesma forma, a publicidade exposta nos ônibus, outdoors, painéis luminosos, os folhetos recebidos nas ruas, o livro, o jornal, cartazes coloridos com informações, anúncios de produtos ou até mesmo poesia espalhados pelas diversas superfícies das estações e paradas, entre outros, fazem com que a pessoa esteja no mundo da mídia bem antes de se dar conta disso. (MEIRELES, 2006, p. 22)

É inevitável, as pessoas estão a todo o momento envoltas pela mídia e, consequentemente, são influenciadas pela publicidade. 
Gonçales (2009, p. 07) ressalta, a respeito da publicidade, que a mesma "engloba todas as formas de comunicação, tornando-se uma técnica comercial de comunicação de massa".

A publicidade ocorre quando a empresa envolvida possui algum bem para ser oferecido ao mercado consumidor, ressaltando que uma vez realizada a publicidade, o fornecedor deve ter meios suficientes para atender a demanda gerada devido a publicidade. (GONÇALES, 2009, p. 09)

Para se elaborar uma publicidade é necessário ter uma ideia, a fim de que seja produzido um anúncio, que fará parte de uma campanha publicitária, após tal medida, a publicidade é inserida num veículo de comunicação, que pode ser televisão, internet e outros.

As primeiras agências de publicidade surgiram ainda em meados do século XIX, uma vez que, com o aumento da produção experimentado com a Revolução Industrial, os bens, que agora eram produzidos em massa, precisavam ser escoados para o mercado consumidor. (GONÇALES, 2009, p. 14)

A televisão, por exemplo é um meio de comunicação que prende a atenção, e se torna um certo refúgio da dura realidade das pessoas, fazendo assim com que essas se baseiem na ficção assistida e no conto de fadas transmitido de forma televisiva.

Assim, pode-se entender que a televisão é um meio de comunicação de grande relevância, possuindo grande poder de influência em todo o planeta, possuindo particularidades diferentes em cada local do globo.

Hoje a televisão representa importante pluralidade no meio social, atendendo todos os gostos, gêneros e necessidades. (MELETTI, 2018, p. 85)

A televisão, portanto, representa a fantasia, os sonhos e proporciona aprendizado, lazer e retira o indivíduo de sua realidade, que nem sempre é boa ou tranquila.

Assim, Meletti (apud MARCONDES 1988, p. 11) afirma:

O elemento vivo das pessoas, seu 'motor', aquilo que as faz ter vontade de viver, não está no real, no cotidiano nem no mundo do trabalho e sim no imaginário. E a televisão é a forma eletrônica mais desenvolvida de dinamizar esse imaginário. Ela é também a maior produtora de imagens.

Resumindo, a televisão, encanta, diverte, emociona e faz com que seus usuários tenham acesso, mediante imagens, a programas que lhe interessam, suprindo necessidades diversas. 
Nessa seara, a televisão representa uma importante forma de publicidade, uma vez que, através de imagens, programas e pessoas podem influenciar as massas.

Samuel Mateus (2011, p.10) salienta o impacto social gerado pela publicidade por essa busca de notoriedade e promoção de atividades comerciais mostrando que:

A publicidade envolve a participação da sociedade e do indivíduo nos processos de decisão colectiva, permitindo a produção, reprodução e transformação de um imaginário comum potenciador de integração e coesão sociais. Esse projecto que se funda não apenas numa racionalidade discursiva, no logos, é também alimentada por outras práticas simbólicas, mais ou menos investidas de conteúdo político, que contribuem para uma comunicação transversal a toda a sociedade. É neste processo que a individualidade e a identidade são moldadas e fixadas, para no momento seguinte sofrerem nova acção reformadora que modifica e acrescenta uma riqueza ímpar ao espólio subjectivo que cada um possuía inicialmente. A esfera pública é o local por excelência de intersecções inter-estratos e inter-culturas colocando-se mais do lado da abertura e novas proposições do que do lado da regra, imutável, sólida e intocável ${ }^{3}$.

A publicidade ganha livre possibilidade de expansão, pela sua legitimidade política e por não ter limites em seus processos de desenvolvimento.

Uma vez que a publicidade não esteja pautada em normas, pode se tornar um influenciador de forma negativa, fazendo com que os telespectadores adotem hábitos ruins, como o consumo excessivo de alimentos pobres em nutrientes, gerar o sedentarismo, entre outros, e tais influências podem ser ainda maiores quando o indivíduo que assiste a televisão não possui condições totais de discernimento, como crianças e adolescentes.

A publicidade tem o condão de influenciar, independentemente da forma como chega ao indivíduo e precisa possuir limites, a fim de não trazer danos à vida e a saúde do indivíduo.

Assim, pode-se afirmar que a publicidade representa um manancial que influencia a opinião pública, e, dessa forma, gerando novos adeptos a teoria sociais, filosóficas e políticas.

Muitas vezes as pessoas acabam sendo influenciadas pelas mídias e nem se dão conta disso, posto que há uma cultura do consumo, que é acentuada pela publicidade, que cada dia

\footnotetext{
${ }^{3}$ Foi mantida a linguagem original.
} 
estão mais diversificadas e presentes nos locais mais inusitados, fazendo com que esteja no cotidiano das pessoas.

Nesse sentido,

A indústria da cultura, no seguimento destas modificações societais, vem contribuir para o aniquilamento de uma esfera pública crítica e de um sujeito activo. Ela condiciona-o, aliena-o, torna-o regressivo numa cultura frívola, árida, e reificada como consequência da sua mercantilização. O económico imiscui-se no cultural, a cultura passa a ser vendida e a sua condição de acesso é a aquisição. Deste modo, a cultura pública tende a privatizar-se, deixa de ser universalmente acessível, reparte-se entre aqueles que a produzem e aqueles que a adquirem, deixa de ser um bem colectivo e polifónico resultado da participação activa dos indivíduos, priva o indivíduo à educação livre do espírito, impede-o de determinar-se, de saber, de conhecer, de formar-se. A cultura, sob o manto da universalidade, torna-se particular e eclética. (SAMUEL MATEUS, 2011, p. 3)

Assim, a influência das mídias e da publicidade, no cotidiano atual são inevitáveis, as massas possuem acesso a diversos meios e mídias, que podem contribuir para a formação de opiniões, cultivando a política da paz ou mesmo de conflitos, gerando consumo consciente ou desenfreado.

\section{MÍDIAS VOLTADAS PARA CRIANÇAS}

A criança e o adolescente, durante muito tempo, foi tratada como um adulto em miniatura, não possuindo direitos ou qualquer tratamento diferenciado ou específico para sua condição de ser em desenvolvimento.

Antes do século XIII a criança sequer foi relatada na sociedade, como em pinturas e esculturas, contudo, somente passou a ser considerada um ser independente do adulto no século XVI. (FERREIRA, 2015, p. 01)

Atualmente não se tem horários específicos de transmissão televisiva para o público infantil, sem que haja intervenção publicitaria, visto que essas estão inseridas também nos programas e animações na atualidade. 
Poucas famílias possuem noção do quanto a televisão, assim como outras mídias podem influenciar negativamente a formação das crianças, uma vez que estas, cada vez mais iniciam o contato com o aparelho mais cedo, não possuindo condições de discernimento.

Dentre os principais problemas que podem ser trazidos para as criança em razão da influência das mídias sociais é o fato de a criança passar a ser movida por vontades passageiras, além de desenvolver características de centralização, uma vez que a criança aprende a querer e achar interessante apenas aquilo que é trazido pela propaganda, se interessando apenas em ter acesso ao bem objeto da publicidade, além do fato de que a publicidade é fantasiosa e pode levar a criança a acreditar apenas no mundo trazido pela publicidade, que é feliz apenas para aqueles que possuem acesso ao produto anunciado. (FERREIRA, 2015, p. 03)

Nesse sentido, Meireles (2006, p. 30) afirmam que:

À medida que a criança aprende (a comer, caminhar, falar, manejar os objetos) vai diminuindo sua onipotência. Seu psiquismo organiza-se e seu ego se fortalece.

O bebê e a criança de tenra idade, enquanto permanecem sentados assistindo a televisão, encontram-se impedidos de utilizar os outros mecanismos mentais, isto é, a introjeção, a sublimação e a reflexão, o que restringe grandemente suas possibilidades de crescimento intelectual.

Cada vez mais os pais estão fora de casa, deixando os filhos na companhia de babás, outros parentes ou mesmo sozinhos e não raro as crianças aprendem cada vez mais novas a tomarem decisões como o que assistir ou o que acessar na internet, porém, nem sempre estão aptas a tomarem tal decisão e acabam tendo acesso a mídias inapropriadas a sua faixa etária. (CABRAL et al, 2012, p. 03)

As mídias voltadas ao público infantil são aquelas direcionadas a indivíduos que possuam entre 0 e 12 anos de idade. Nessa seara, o marketing infantil é aquele voltado para pessoas que se encontrem nessa faixa etária, analisando necessidades como alimentação, vestuário, dentre outros, dessa forma,

Marketing é troca para benefício de todos. Marketing é troca responsável. O marketing infantil deve ser praticado através destas duas dimensões de necessidades - fornecemos emoções em busca de fascínio imediato de nossas crianças ao mesmo tempo em que as preparamos para o futuro. Não é difícil 
perceber que a construção do futuro delas é a construção do nosso próprio futuro. (MEIRELES, 2006, p. 13)

O marketing infantil, portanto, precisa ser responsável, visando o bem-estar do público atendido.

As crianças possuem muito mais facilidade com as novas tecnologias, sendo comum, inclusive, que tenham mais conhecimento que pais e avós, dessa forma, é comum que acessem, sem serem descobertas sites e publicidade inapropriada.

Nesse sentido, temos que, na criança, tudo é emoção, sendo que qualquer produto que possa despertar emoções como alegria, tristeza, amor, entre outros e o marketing tem o dever de suprir tais necessidades, porém, fazer com que a criança sinta emoções apenas consumindo é extremamente perigoso. (MEIRELES, 2006, p. 15)

O público infantil é, de todas as posições sociais, o alvo mais fácil de ser atingido e conquistado, assim o programa Criança e consumo, do Instituto Alana mostra que:

O que caracteriza a abusividade da publicidade dirigida à criança é, principalmente, o fato de ela se aproveitar da ingenuidade dos pequenos para lhes vender produtos. Pelo fato de a maioria das crianças acreditar no que ouve e vê, ela também acredita que o produto ou o serviço anunciado vai realmente proporcionar-lhe os benefícios e os prazeres que a publicidade promete. Mesmo que se trate de algo absolutamente irreal e impossível de se realizar. Um adulto pode compreender que o tênis de marca anunciado não vai deixálo tão famoso e rico como o astro esportista que está protagonizando o comercial televisivo. Já a criança desejará o produto por acreditar, por exemplo, que terá um poder diferenciado se tomar um achocolatado; ou que entrará em um mundo encantado se comprar determinado brinquedo. Tratase, portanto, de um jogo desigual, no qual quem anuncia para crianças sabe o que está fazendo, enquanto elas não sabem exatamente o que estão comprando. (INSTITUTO ALANA, 2018, p. 01)

Nesse sentido, tem sido comum que pais e organizações da sociedade civil buscarem combater a propaganda abusiva direcionada para crianças, uma vez que estes indivíduos ainda estão em formação e, na maioria dos casos não são aptos para selecionar produtos que realmente necessitam ou ainda que tragam benefícios para o seu bem-estar. 
Muitas publicidades direcionadas para crianças e adolescentes trazem como foco a venda casada ou brindes, que somente são acessíveis a partir do momento que há o consumo do produto ou serviço ofertado pela empresa.

A publicidade exercida pela televisão já é motivo de preocupação de muitos especialistas, devido ao fato de tal mídia, assim como outras, como a internet exercerem forte influência sobre qualquer público, em especial as crianças.

Hoje em dia existem programas voltados para todos os públicos infantis, desde bebês, sendo que muitos prometem auxiliar no desenvolvimento da criança, contudo, o fato de programas incentivarem o consumo preocupa. (CABRAL et al, 2012, p. 05)

Crianças são facilmente atraídas por brinquedos, cores e personagens de seus programas favoritos, o que faz com que sejam "presas fáceis" para a publicidade e o consumo instigado por muitas empresas.

Tentando evitar excessos quando se trata do público infantil, Cabral et al (2012, p. 05): "Em 2006, o CONAR - Conselho Nacional de Auto-regulamentação Publicitária - introduziu novas regras nesse sentido no Código Brasileiro de Ética Publicitária - CBARP, principal documento normativo que guia as decisões do organismo".

O Conar é um órgão não governamental que atua na prevenção e repressão da publicidade abusiva ou enganosa.

O impacto que influencia no crescimento da criança, através da televisão é motivo de preocupação pelo mal que faz, sendo algo que poderia desenvolver resultados positivos e eficazes para uma vida e convívio social futuro saudáveis.

Assim:

O debate que põe em questão a educação na televisão vem discutindo as maneiras adequadas de se transmitir a uma criança, por exemplo, um conteúdo educativo e lúdico ao mesmo tempo, sem prejudicar sua formação. Isso envolve uma série de fatores como o conteúdo, a linguagem, o contexto da recepção por parte do telespectador, como até mesmo a qualidade de vida da criança. O importante é considerar nas mídias a imaginação infantil articulada aos demais processos cognitivos, afetivos e socioculturais; e isso, pode ser representado e explorado pelo uso do fantoche na televisão. A imaginação da criança é o que faz com que ela reaja às novidades que o mundo lhe oferece, para assim pressentir ou esboçar possibilidades futuras. Com isso, a emoção vivida pela criança através das brincadeiras se torna muito importante, ou seja, 
as histórias e manifestações artísticas que a cultura lhe oferece vão ser assimiladas e recriadas pela criança, juntamente com o contato com a arte e a natureza e o apoio do adulto. A televisão permite que a criança crie a habilidade de montar um sentido a partir de um conjunto descontínuo de imagens, desenvolvendo uma atenção mais larga e a habilidade de fazer muitas coisas ao mesmo tempo e bem, além do rápido processamento da informação visual. A ideia é que a mídia nutra a imaginação da criança e não a substitua. (MELETTI, 2018, p. 114)

Vale ressaltar também que nos dias atuais a televisão não é somente o único meio de ligação da criança ao mundo publicitário capitalista. Hoje pode-se perceber que as crianças, de modo geral têm acesso livre a esse expandido mundo que é a internet, visando livre acesso a portais de vídeo, como o Youtube, navegadores, e outras mídias.

As crianças estão cada vez mais inseridas em meios de correntes publicitárias. E essas estão camufladas, além de cruas publicidades comerciais, também se encontram nos famosos vídeos de comentários sobre desenhos animados, filmes, musicas, etc. Trazendo assim uma visão adulta ao meio infantil.

De acordo com Cabral et al (2012, p. 03) a televisão representa um importante influenciador no consumo infantil, movimentando mais de 15 bilhões de dólares todos os anos, sendo que em média são mais de 40 mil publicidades voltadas para esse público que são transmitidas anualmente.

Certamente não é de se espantar os valores em análise, uma vez que o público infantil é muito mais vulnerável, já que se trata de seres em formação, que ainda são incapazes de discernir suas preferências.

Insta salientar, conforme expõe Ferreira (2015, p. 02):

Sendo assim, entende-se que a criança, embora reconhecida como portadora de inteligência extremamente ativa, esteja mais exposta às mensagens publicitárias, não tendo condições de perceber e avaliar o caráter de parcialidade das informações, de entender que as mesmas representam o ponto de vista de um anunciante. 
A internet também é uma mídia bastante acessada pelas crianças de diversas idades, principalmente no que diz respeito aos games, que representam mais de $83 \%$ do conteúdo acessado por este público. (CABRAL et al, 2012, p. 03)

As crianças brasileiras representam uma das que mais permanecem na frente da TV, sendo a média de 3 horas e 30 minutos por dia, enquanto que, por exemplo, nos Estados Unidos, tal índice representa 3 horas e 16 minutos. (MEIRELES, 2006, p. 31)

Assim, o Projeto Alana salienta que atualmente as crianças também estão sendo influenciadas a buscar alcançar suas vontades, conquistando espaço no mundo apenas se tiverem algo,

Cada vez mais as crianças têm sido o alvo preferencial de apelos comerciais e ações de marketing, mesmo que ainda não estejam preparada para lidar com as complexas relações de consumo. Mal sabem falar, mas já conhecem marcas e logotipo. Nos primeiros passos já são espectadoras fiéis de programas televisivos e de seus personagens, depois amplamente reproduzidos em embalagens, materiais escolares, roupas, brinquedos, sapatos, produtos de higiene. (INSTITUTO ALANA, 2018, p. 01)

Assim, a proteção da criança e do adolescente é indispensável, a fim de garantir que possam se desenvolver de forma saudável.

O mais importante é garantir o direito de as crianças vivenciarem todas as etapas de seu crescimento e, aos poucos, ensiná-las valores mais humanos e menos materialistas. Ser feliz nada tem a ver com possuir bens materiais e status social. Também é fundamental que até os 12 anos as crianças sejam protegidas dos apelos para o consumo e que aprendam a lidar com o consumo sempre com a mediação dos adultos. Só assim elas serão capazes de desenvolver espírito crítico. (INSTITUTO ALANA, 2018, p. 01)

O desejo voltado para o consumo está cada vez mais atingindo a infância, e isso se torna uma questão preocupante, visto que a ideia de formação de opinião começa a ser substituída e alterada pelo desejo de aquisição. Assim os valores que as crianças deveriam ter como princípios começam a ser manipulados, e decorrente dessa manipulação o público infantil se encontra pronto para a inserção precoce nesse ciclo de consumismo. Tal problemática inserida na infância pode acarretar os seguintes problemas, como aponta estudos do Instituto Alana (2018, p. 01): o "aumento exacerbado do consumo; aumento da geração de resíduos; 
obesidade infantil; adultização da infância e erotização precoce; consumo precoce de álcool e tabaco; diminuição das brincadeiras criativas; violência; estresse familiar”.

Com o desejo de consumo inserido em suas vidas, as crianças começam a desejar objetos ofertados, não se limitando às suas possibilidades, trazendo assim para suas vidas, frustrações e dificuldades pessoais para se inserirem em grupos de outras crianças nas escolas e vizinhança, por não se verem aptas e ingressar no contexto de outro grupo. Assim também acarretam outros possíveis problemas futuros, como mostra a seguir:

Crianças e adolescentes estão em fase de construção de suas identidades, motivo pelo qual a aceitação em seus grupos é muito importante para eles. A publicidade se aproveita disso para incutir neles a necessidade de terem produtos de marca para sentirem-se incluídos socialmente. Seduzir uma criança a desejar um produto que não está ao alcance de suas possibilidades é o mesmo que lhe dizer: “Aqui está o tênis incrível que você não vai ter”. Essa impossibilidade recorrente de possuir os produtos anunciados vai multiplicando a intolerância da criança às negativas que recebe. Então, transtornada pela frustração, ela pode decidir obter à força o objeto do seu desejo. Nesse caso, a decisão de roubar é a "chance torta" que o indivíduo dá a si mesmo, de ouvir o tão sonhado "sim, você tem direito, leve o que quiser". Mesmo que seja à custa de uma arma apontada para o doador involuntário. (INSTITUTO ALANA, 2018, p. 01)

Esses problemas acima citados dos desejos impulsionados pela publicidade fazem que os grupos sociais estejam cada vez mais distantes um do outro, gerando assim uma desunião social, o que gera desigualdade elevada e também o preconceito, já por terem em mente, desde a infância as desiguais oportunidades e possibilidades.

Pesquisas recentes apontam que as crianças podem influenciar em até $80 \%$ as decisões de consumo das famílias, conforme explana Salla (2018, p. 01):

Pesquisas apontam que, no Brasil, as crianças influenciam em até $80 \%$ as decisões de consumo das famílias. E o mercado publicitário faz de tudo para vender toda sorte de produtos aos pequenos. Alegando que essa overdose de publicidade é danosa para as crianças, um projeto em votação na Câmara dos 
Deputados quer proibir a propaganda voltada para jovens de até 12 anos na TV. Para os contrários à lei, a proibição é uma medida autoritária e inútil.

A lei poderá trazer ainda mais revolta e certamente será impossível controlar totalmente a publicidade voltada para o público infantil, uma vez que são diversas as formas de mídias e formas de serem acessadas.

É interessante ressaltar que proibir totalmente a publicidade direcionada para crianças pode não ser a solução do problema, que será melhor resolvido com educação, tanto para pais, filho, sociedade e órgãos governamentais.

Dessa forma, explica Lott (2018, p. 01):

A educação para o consumo deve ser o foco da discussão sobre a publicidade voltada para o público infantil, segundo as especialistas que participaram da última edição do Arena no Marketing, programa mensal promovido pelo Folha em parceria com a ESPM (Escola Superior de Propaganda e Marketing) e que teve mediação da jornalista Laura Mattos. A proibição desse tipo de propaganda não é a saída mais adequada.

O Conar é um importante órgão que atua na proteção de crianças e adolescentes, a fim de se evitar o acesso a publicidade de cunho nocivo, abusivo ou que possa trazer alguma influência negativa para o desenvolvimento desse público, como o acesso a bebidas alcoólicas, cigarro, entre outros.

Outra questão a ser levada em consideração como consequência das mídias que direcionam em excesso as correntes publicitárias para as crianças é a obesidade, como aponta dados de pesquisas realizadas pelo (INSTITUTO ALANA, 2018, p. 01), através do projeto Criança e Consumo:

A obesidade infantil cresce em um ritmo assustador e já atinge $15 \%$ da população infantil brasileira. Segundo o IBGE, o sobrepeso entre crianças dobrou os últimos 34 anos e está intimamente relacionado ao aumento do consumo de alimentos industrializados, amplamente divulgados pelo mercado produtor e distribuidor. (...) A publicidade alimentos não saudáveis estimula o consumo excessivo de produtos industrializados e agrava o aumento dos índices de sobrepeso e obesidade infantil. 1 em cada 3 crianças de 5 a 9 anos 
está acima do peso e o sobrepeso dobrou nos últimos 34 anos, segundo dados da POF 2008-2009, produzidos pelo IBOPE.

No hall das mídias publicitarias voltadas para as crianças também encontramos aquelas de conteúdo adulto, sem cuidados e limites que as possibilitem ser assistidas pelo público jovem, que engloba também o infantil, se tornando assim atrativas para tal público. Deste gênero publicitário podemos citar as publicidades e propagandas de bebidas alcóolicas transmitidas pelo meio televisivo ou incorporadas em portais de navegação, sendo estes encontrados mesclados em atrativos na internet, como anúncios em vídeos, navegadores e sites.

Os anúncios de bebidas alcoólicas podem influenciar no precoce uso das mesmas, sendo este uso iniciado ainda na adolescência, ou em outra fase da vida adulta, mas por tal influência na infância:

Em relação ao consumo precoce de álcool, $62 \%$ dos adolescentes brasileiros afirmaram terem sido expostos quase todos os dias, até mais de uma vez por dia, a publicidades de bebidas alcoólicas, de acordo com pesquisa da Unifesp de 2009. A idade na qual se inicia o consumo regular de bebidas alcoólicas no Brasil está entre 12 e 14 anos. (INSTITUTO ALANA, 2018, p. 01)

Infelizmente, em razão do trabalho ou outros tantos motivos, os pais não conseguem controlar o que seus filhos veem, e, em muitos casos não é preciso nenhum esforço da criança ou adolescente para ter acesso a tais publicidades.

Assim o procurador do Ministério Público Federal Fernando Lacerda Dias discorre sobre o assunto em pesquisa feita pelo Instituto Alana (2018, p. 01):

Esse é um dos fundamentos dessas ações que eu propus contra as publicidades específicas. O próprio Código de Auto-regulamentação Publicitária do Conar prevê que publicidades de cerveja não podem ser atrativas para o público jovem. E quase todas elas são. Usam humor, linguagem juvenil e até símbolos e personalidades que atraem esse público. Não existe nenhuma lei, nenhuma norma que controle isso no Brasil. Consequentemente, não há nenhum órgão público que faça essa fiscalização. Então, o único controle é do Conar.

E ainda expõe sua visão crítica: 
As normas de auto-regulamentação são limitadas, embora representem algum avanço. Mas a aplicação e a fiscalização dessas normas pelo Conar são totalmente falhas. O Conar não tem uma preocupação realmente efetiva em fiscalizar. Não tem poder porque não pode aplicar multas. Ele não pode, sequer, determinar alguma coisa. Ele apenas recomenda. E, mesmo assim, faz de maneira bastante tímida. Muitas vezes, o Conar fiscaliza a questão da concorrência - se alguma marca se sentiu lesada pela publicidade de outra. E quando recomenda a suspensão de uma campanha, ela já saiu do ar. Não faz sentido, fica uma coisa inútil. Na prática, essas empresas de cerveja fazem publicidade do jeito que querem. (INSTITUTO ALANA, 2018, p. 01)

Nesse sentido, qualquer pessoa que tenha o conhecimento de publicidade abusiva contra crianças e adolescentes, pode denunciar, a fim de que possa acontecer punições aos infratores, uma vez que o público infanto-juvenil pode ser bastante prejudicado por mídias e publicidade que tenha teor prejudicial a sua formação e consumo.

\section{DIREITOS DA CRIANÇA E DO ADOLESCENTE E O DEVER DE PROTEÇÃO}

Os direitos da criança e do adolescente começaram a ser positivados no Brasil a partir de meados do século XX, com tratativa diferenciada e reconhecimento da vulnerabilidade mais especificamente após a Constituição Federal de 1988 e do ECA.

Antes disso a criança era vista como um adulto em miniatura, sendo que os direitos previstos eram mais voltados para a proteção dos órfãos ou indivíduos em situação de grande pobreza. (CABRAL, 2012, p. 03)

Vale ressaltar, primeiramente o que tange e o bem jurídico protegido pelo Estatuto da Criança e do Adolescente, que é a proteção integral da criança e do adolescente.

A criança e o adolescente, como sujeitos de direitos, têm assegurados todos os direitos fundamentais do ser humano. A tais garantias somam-se outras, especificamente criadas para assegurar seu desenvolvimento saudável, como a garantia à convivência familiar e a proteção contra qualquer forma de negligência, exploração, etc. A esse arcabouço de proteção jurídica à criança e ao adolescente dá-se o nome de 'proteção integral'. Porém, apesar de tais 
disposições, as estratégias de marketing dirigidas ao público infantil ofendem frontalmente o princípio constitucional de não exploração infantil. Isso porque, ao colocar a criança como alvo da mensagem publicitária, contribuem para a violação do direito de liberdade, garantido a todas as pessoas. Como demonstrado, a criança, por seu estágio de desenvolvimento mental e emocional em curso, muitas vezes não é capaz de se posicionar e de se autodeterminar frente à publicidade. Sendo facilmente induzida, seu direito de escolha fica limitado. A exploração da criança pela mídia e pelo mercado publicitário favorece a erotização precoce, a delinquência, a obesidade infantil, o materialismo e o desgaste das relações familiares. (INSTTUTO ALANA, 2018, p. 01)

$\mathrm{O}$ artigo $4^{\circ}$ do Estatuto da Criança e do Adolescente prevê em seu caput que é dever da família e de toda a sociedade, além do Poder Público, zelar pelo bem-estar de crianças e adolescentes, devendo estes terem prioridade quanto à efetivação de direitos como educação, saúde, lazer, esporte, entre outros.

Os direitos da criança e do adolescente priorizam uma vivência saudável, sem a interferência prejudicial de mídias ou quaisquer outros meios que possam comprometer a qualidade de vida do indivíduo em formação.

Como dever da família pode-se apontar que:

Pais e responsáveis devem dialogar com seus filhos e impor limites. Dizer "não" a cada pedido de consumo desnecessário é muito importante para que a criança aprenda a lidar com frustrações e entender que suas ações podem ter impactos no coletivo. Também é importante dar o exemplo de ensinar as crianças a fazer algumas reflexões a cada novo pedido: "preciso realmente comprar isso?", “já não tenho algo parecido que possa ser reaproveitado?". (INSTITUTO ALANA, 2018, p. 01)

Assim, os pais devem depositar atenção reforçada ao meio em que seus filhos estão inseridos, como os meios de entretenimento, visto que são responsáveis que estão presentes para orientação e cuidado da criança, com o reforço e apoio do Estado. Ou assim é a forma como deveria ser. 
Mas a família, por si só, não consegue manter esse cuidado e impor certos limites a todo tempo na rotina diária da criança. E assim o Estado deveria atuar durante essas brechas que faltam atenção. Como, por exemplo, durante o período escolar e em uma melhor restrição e limitação de conteúdo para certos anúncios publicitários.

Além disso, as empresas precisam agir com ética, a fim de preservar os direitos das crianças e adolescentes, de forma a olhar para a infância como um período importante do indivíduo, pois é o momento em que suas convicções e personalidade começam a se formar.

Crianças e adolescentes não devem ser tratados apenas como pequenos consumidores, uma vez que não possuem entendimento para tanto, posto que não estão aptas a discernir sobre a questão.

Nesse sentido, temos o ECA: “Art. 18 É dever de todos velar pela dignidade da criança e do adolescente, pondo-os a salvo de qualquer tratamento desumano, violento, aterrorizante, vexatório ou constrangedor".

Dessa forma, os apelos relacionados a consumo envolvendo crianças e adolescentes devem ser direcionados aos pais e não aos filhos. (INSTITUTO ALANA, 2018, p. 01)

E em reforço de defesa ao referido acima, o artigo 76 do Estatuto da Criança e do Adolescente versa que: “Art. 76 As emissoras de rádio e televisão somente exibirão, no horário recomendado para o público infanto-juvenil, programas com finalidades educativas, artísticas, culturais e informativas".

Com a Constituição Federal de 1988 a criança e o adolescente ganharam maior proteção, que foi ampliada com o Estatuto da Criança e do Adolescente.

Atualmente a criança recebe atenção integral da legislação, bem como proteção, cabendo aos pais e outros responsáveis garantir o amplo acesso ao básico e essencial para uma vida com dignidade.

Nessa seara, a proteção contra questões que envolvam abusos publicitários não pode ser esquecida, pois as crianças não podem ser alvo de consumismo exacerbado ou ainda frustrações demasiadas em razão da impossibilidade de consumir.

O Estatuto da Criança e do Adolescente (ECA) é a legislação que explicita a implementação da proteção integral constitucionalmente estabelecida no artigo 227. Assim, estabelece medidas concretas para a garantia dos direitos de crianças e adolescentes. Responsabiliza nominalmente a família, a comunidade, a sociedade e o Estado pelo bem-estar e saudável 
desenvolvimento da infância e da juventude. Enquanto o artigo $4^{\circ}$ indica a preservação da liberdade, o artigo 17 garante a preservação da autonomia das crianças e adolescentes. O marketing infantil ignora esses direitos fundamentais e invade o espaço infantil, rompendo com a preservação da integridade deles. Por não conseguir se posicionar criticamente frente a uma publicidade, a criança tem o seu direito de liberdade e capacidade de autodeterminação violados. A dificuldade de exercício desses direitos fundamentais ameaça sobremaneira a existência digna dessas pessoas, que terão seu desenvolvimento comprometido.

A conjugação dos artigos $4^{\circ}, 18$ e 76 conduz à conclusão de que a responsabilidade da violação dos direitos de crianças pelas ações de marketing infantil é de todos. Consequentemente, é repudiada qualquer ação que contribua para a perpetração de tais violações. É exemplo de atitude que viola os direitos e a dignidade humana das crianças aproveitar-se da credulidade ingênua delas ao expô-las a publicidades que lhes são especialmente dirigidas. Ações como essa violam frontalmente as previsões estatutárias e constitucionais, atingindo significativamente os direitos fundamentais das crianças. (INSTITUTO ALANA, 2018, p. 01).

Nesses termos, o artigo 227, caput da Constituição Federal trata da questão envolvendo a família, uma vez que esta é a base da sociedade e deve ser respeitada. Assim, nenhum de seus membros pode ser objeto de violação de direitos, cabendo tanto à família, como ao Estado e a comunidade zelar para que haja integral proteção para todos.

Conforme analisado, no Brasil, a legislação envolvendo publicidade voltada para crianças e adolescentes é mediana se comparada com outros países, aonde, em especial na Europa, existe mais restrição, como na Alemanha, em que é proibida a interrupção de programas infantis para fins publicitários, ou ainda a Suécia, em que é proibida qualquer publicidade voltada para esse público. (CABRAL et al, 2012, p. 05)

Há ainda o Código de Defesa do Consumidor, que traz um dispositivo específico que protege a criança e o adolescente contra propaganda abusiva e enganosa, in verbis:

Art. 37. É proibida toda publicidade enganosa ou abusiva.

(...)

$\S 2^{\circ}$ É abusiva, dentre outras a publicidade discriminatória de qualquer natureza, a que incite à violência, explore o medo ou a superstição, se 
aproveite da deficiência de julgamento e experiência da criança, desrespeita valores ambientais, ou que seja capaz de induzir o consumidor a se comportar de forma prejudicial ou perigosa à sua saúde ou segurança.

Dessa forma, a criança possui pouco ou nenhum discernimento a respeito da publicidade, devendo haver filtros, limites e respeito, de acordo com suas características e particularidades.

Nesses termos, o CDC protege todo tipo de consumidor, inclusive as crianças e em especial estas, uma vez que são mais vulneráveis e estão em estágio de desenvolvimento.

\section{CONCLUSÃO}

Diante de tudo que foi exposto, é possível entender que a publicidade em mídias sociais ou ainda através da televisão possui grande influência no cotidiano das famílias.

Entretanto, quando essa publicidade é direcionada ao público infantil, tal questão se torna assunto ainda mais sério, uma vez que as crianças e adolescentes, uma vez que são sujeitos em formação, não possuem o total discernimento, a fim de filtrar os bens que serão úteis e são necessários em seu cotidiano, gerando consumidores desenfreados e inconscientes.

A família, a comunidade como um todo e o Estado possuem a obrigação de proteger a criança e o adolescente de todas as formas de abuso e violência, inclusive no que cabe a publicidade e propaganda apelativas e que podem influenciar negativamente na formação do indivíduo.

A criança e o adolescente devem ser orientados acerca do consumo consciente, bem como a respeito do valor dos bens, a fim de que possam se tornar consumidores responsáveis, que não irão comprar apenas em razão da publicidade, mas sim após analisar o contexto, inclusive sobre a necessidade ou não da aquisição.

A legislação possui um papel crucial na proteção do público infanto-juvenil de publicidade excessiva e abusiva, uma vez que deve nortear e orientar empresas, bem como pais e toda a comunidade a respeito do assunto, a fim de que seja possível discernir as publicidades prejudiciais das demais.

A proteção da criança e do adolescente vai muito além das violências explicitas, pois, uma publicidade abusiva e em desacordo com a situação de indivíduo em formação pode trazer tantos danos para o menor de idade quanto outras espécies de abusos. 
Assim, é responsabilidade dos pais e de toda a comunidade, bem como do Estado zelar para que as crianças e adolescentes estejam protegidos, assim como analisar se o conteúdo de publicidades em redes sociais ou mesmo televisão estão de acordo com a faixa etária indicativa.

É essencial que todos zelem pelo bem-estar e dignidade humana das crianças e dos adolescentes, uma vez que estes representam o presente e o futuro do país.

O Instituto Alana, assim como outros órgãos não governamentais atuam fortemente quando o assunto é o público infanto-juvenil e o consumo, sendo essencial que existam mais leis de proteção a esse público, bem como maior fiscalização, tanto por parte de pais, comunidade, como órgãos governamentais.

\section{BIBLIOGRAFIA}

BRASIL. Constituição de $1988 . \quad$ Disponível em: http://www.planalto.gov.br/ccivil_03/constituicao/constituicao.htm. Acesso 18 julho 2018.

. Lei 8.069, de 13 de julho de 1990. Dispõe sobre o Estatuto da Criança e do Adolescente e dá outras providências. Disponível em: http://www.planalto.gov.br/ccivil_03/leis/L8069.htm. Acesso 18 julho 2018.

Lei 8.078, de 11 de setembro de 1990. Dispõe sobre a proteção do consumidor e dá outras providências. Disponível em: http://www.planalto.gov.br/CCivil_03/Leis/L8078.htm. Acesso 18 julho 2018.

CABRAL, Adilsonet al. A publicidade infantil no Brasil e suas implicações ético-legais: estudo empírico em campanhas voltadas ao Dia da Criança. Revista temática, 2012. Disponível em: http://www.insite.pro.br/2012/Dezembro/publicidade_infantil_brasil.pdf. Acesso 18 julho 2018.

GONÇALES, Márcio Carbaca. Publicidade e Propaganda. Curitiba: IESDE Brasil S.A., 2009.

GONZALES, Lucilene dos Santos. Agência experimental de propagandas sociais [recurso eletrônico ]: pesquisa e prática. São Paulo: Cultura Acadêmica, 2018.

FERREIRA, Adriana R. Publicidade infantil: impactos sobre o desenvolvimento da criança. Intercom - Sociedade Brasileira de Estudos Interdisciplinares da Comunicação. XXXVIII Congresso Brasileiro de Ciências da Comunicação. Rio de Janeiro, RJ-4 a 7/9/2015. Disponível 


\section{PUBLICIDADE E PÚBLICO INFANTIL: A INFLUÊNCIA DE MÍDIAS SOCIAIS E A PROTEÇÃO DA INFÂNCIA}

em: http://portalintercom.org.br/anais/nacional2015/resumos/R10-1163-1.pdf. Acesso 10 julho 2018.

INSTITUTO ALANA. Criança e consumo. Disponível em: http://criancaeconsumo.org.br/consumismo-infantil/. Acesso 10 julho 2018.

LOTT, Diana. Publicidade infantil deve ser feita com responsabilidade em vez de proibida, dizem especialistas. Folha de São Paulo. Disponível em: https://www1.folha.uol.com.br/mercado/2018/05/publicidade-infantil-deve-ser-feita-comresponsabilidade-em-vez-de-proibida-dizem-especialistas.shtml. Acesso 10 julho 2018.

MEIRELES, Fabiana Melo. A influência da publicidade no comportamento infantil. Trabalho apresentado à banca examinadora da FASA (Faculdade de Ciências Sociais Aplicadas), para conclusão do curso Comunicação Social, habilitação em Jornalismo. Brasília: UniEUB, 2006. Disponível em:

http://repositorio.uniceub.br/bitstream/123456789/1447/2/20061826.pdf.Acesso 10 julho 2018.

MELETTI, Giulia Filippini. Do radio à televisão: Propagandas Minuto Consciente para o público infantil. Agência experimental de propagandas sociais. Lucilene dos Santos Gonzales. Cultura Acadêmica, 2018.

SALLA, Fernanda. A publicidade deve ser proibida para crianças? Superinteressante. Disponível em: https://super.abril.com.br/mundo-estranho/a-publicidade-deve-ser-proibidapara-criancas/ Acesso 10 julho 2018.

SAMUEL, Mateus. Publicidade e Consumação nas Sociedades Contemporâneas. Portugal Covilhã: Lab Books, 2011. 